\title{
Effect of Bleomycin, Etoposide, and Cisplatin Treatment on Spermatogonia Cell and Malondialdehyde Level in Male Rats
}

\author{
Nur Budaya T, Surya Putra T, Daryanto Besut, Anita Kenty W
}

\begin{abstract}
Co-administration of bleomycin, etoposide, and cisplatin (BEP) becomes standart chemotherapy for testicular cancer because it has brought a cure rate of more than $90 \%$. Impact of the treatment to the outcome become a concern, particularly the adverse effect on a long-term reproductive health risk to cancer survivors. There is no evidence, when the damage to the testes began due to the administration of BEP chemotherapy, makes the indication of treatment still controversial. The aim of this study is to determine the effects of BEP on Spermatogonial cell and MDA levels outcome in an animal model. Male wistar rats (Rattus norvegicus) aged 13-15 weekswere treated daily with BEP for three cycles, 33 hours each. It was divided into one control group received 1cc of normal saline, and three groups received three cycles of $0.5 x$ dose-levels of BEP (Intraperitoneally; $0.75 \mathrm{mg} / \mathrm{kg}, 7.5 \mathrm{mg} / \mathrm{kg}$, and $1.5 \mathrm{mg} / \mathrm{kg}$ ). Cell number of Spermatogonia cells were calculated from $\mathrm{HE}$-stained specimens and observed under light microscope (Olympus BX-51) using 400x magnification (high power field) Thiobarbituric acid (TBA) test method used to measure malondialdehyde (MDA) level by spectrophotometry. The result was a significant decrease in the average number of Spermatogonia cells $(p=0.003)$ between the control group and others. This is caused by excessive exposure to BEP chemotherapy, which cause atrophy of the seminiferous tubules and content of germ cells in the tubules has decreased, accompanied by the appearance of immature germ cells that enter the lumen. A significant increase in MDA levels $(p=0.001)$ occurred after the administration of the third cycle of BEP chemotherapy. In conclusion, BEP chemotherapy adversely affect the number of Spermatogonia cells and MDA level. The third cycle BEP chemotherapy significantly more destructive compared to the first and second cycle.
\end{abstract}

Keywords: BEP chemotherapy, male germ cells, malondialdehyde.

\section{INTRODUCTION}

$\mathrm{T}$ esticular cancer represents $1 \%$ of all malignancies in men and accounts about $5 \%$ of all urinary tract cancer events. ${ }^{1}$ The occurrence of testicular cancer mainly occurs in

Revised Manuscript Received on January 2, 2020.

* Correspondence Author

Nur Budaya T*, Department of Urology, Faculty of Medicine, Universitas Brawijaya, Malang, Indonesia, Email: taufiq_fkub03@yahoo.com

Surya Putra T. Department of Urology, Faculty of Medicine, Universitas Brawijaya, Malang, Indonesia

Daryanto Besut, Department of Urology, Faculty of Medicine, Universitas Brawijaya, Malang, Indonesia

Anita Kenti W, Department of Pathology Anatomy, Faculty of Medicine, Universitas Brawijaya, Malang, Indonesia men aged 18-35 years and often causes the morbidity and mortality. In the past 10 years, the incidence of testicular cancer has increased in developing countries, that is around $5-10$ new cases per 100,000 population per year. ${ }^{2}$ Risk factors for testicular cancer include a family history of testicular cancer (relative risk $(\mathrm{RR}) \approx 8-10$ from relatives), cryptorchism $(\mathrm{RR} \approx 4-8)$, and previously diagnosed with testicular cancer on the contralateral side $(\mathrm{RR} \approx 25)$. Increased incidence of testicular cancer is associated with decreased fertility in men. ${ }^{3}$ Multimodal management of testicular cancer includes surgery, chemotherapy, and radiotherapy.

The combination of BEP chemotherapy in testicular cancer is very effective in reducing progression, and extending life expectancy to above 5 years is around $95 \% .^{5}$ Most anticancer drugs are cytotoxic, which interferes with testicular function in humans and animals ${ }^{5,6}$, which eventually results in infertility and endocrine dysfunction. Administration of BEP therapy in three cycles for 21 days can induce germ cell death, DNA damage and results in rat infertility. ${ }^{5,6}$

BEP chemotherapy can induce oxidative stress as a mechanism of toxicity of some cells. Increased intracellular Reactive Oxygen Species (ROS) can produce DNA damage, lipid oxidation, and protein oxidation. DNA damage in very large numbers, can cause mutations, eliminate the genetic integrity of all cells, and trigger apoptosis. Oxidative stress can also induce cellular membrane damage that results in fat peroxidation, thereby changing unsaturated lipids into polar lipid hydroperoxides. Lipid peroxidation also plays a role in producing several oxidation products, such as epoxide and MDA, which can be measured as markers of oxidative stress.

BEP chemotherapy increases the expression of proto-oncogenes and stimulates the formation of oxidative stress, causing permanent damage to Leydig cells and Sertoli cells ${ }^{5}$, induces DNA hypo-and hyper-methylation ${ }^{8}$ other epigenetic modifications. Male rats treated with BEP chemotherapy can show disruption of the germ cell epithelium, which later will experience infertility ${ }^{7}$, and even if significant effects of the drugs have been lost, the rat still has disruptive fertility effects such as continuous loss of pre-implantation and abnormal morphological offsprings. ${ }^{9}$

Exposure to BEP chemotherapy can cause sperm DNA damage, induce the breakdown of single and double strand DNA, decrease chromatin density, induce telomere 


\section{Effect of Bleomycin, Etoposide, and Cisplatin Treatment on Spermatogonia Cell and Malondialdehyde Level}

in Male Rats

shortening in the spermatogenesis stage, damage to seminiferous tubular structures and testicular organs that occur after 3 to 6 months of administration chemotherapy BEP. ${ }^{10,11}$

Prolonged chemotherapy can also stimulate the formation of expression of oxidative stress responses in the testes, the end result of which can induce damage from the germ cell pathway. ${ }^{5}$ Until now it has not been known with certainty that damage has occurred to the testes due to the administration of BEP chemotherapy, so that intervention on patients undergoing chemotherapy cannot be known with certainty, so researchers want to examine the start of damage to the testes due to BEP chemotherapy.

\section{MATERIALS AND METHODS}

\section{A. Animals}

13-15 weeks-old male Rattus novergicus weighed 300-350 grams were maintained in the Animal Resources Center at Laboratory of Pharmacology, Faculty of Medicine, Universitas Brawijaya. The animals were divided into four groups of 6 rats each. After the treatment, all rats euthanized by using ketamine injection and the testis was removed for further analysis. All of procedure performed in this study has been approved by Ethical Committee of Medical and Health Research, Faculty of Medicine, Universitas Brawijaya (400/043/K.3/302/2019).

\section{B. BEP treatment protocols}

The dose-levels of BEP chemotherapy protocol for cancer patients are bleomycin, $30 \mathrm{mg} /$ week; etoposide, 100 $\mathrm{mg} / \mathrm{m}^{2}$; and cisplatin, $20 \mathrm{mg} / \mathrm{m}^{2}$. The body surface area adjusted doses to the rat are bleomycin; etoposide; and cisplatin $(1.5 ; 15 ; 3 \mathrm{mg} / \mathrm{kg}){ }^{5,9}$ The effects of the three cycles of the chemotherapy were evaluated, the animals were randomly divided into four groups as follows. One control group received only $1 \mathrm{cc}$ of normal saline, and the three groups received (intraperitoneal injection) three cycles of 0.5 $x$ dose-levels of BEP $(0.75 \mathrm{mg} / \mathrm{kg}, 7.5 \mathrm{mg} / \mathrm{kg}$, and 1.5 $\mathrm{mg} / \mathrm{kg}$ ). Premedication with dexamethasone $5 \mathrm{mg}$ were given 30 minutes prior to BEP chemotherapy. Thirtythree hours after the first cycle of BEP, rats in control group and one BEP group were sacrificed. The other groups of rats were sacrificed after 66 hours and 99 hours of BEP chemotherapy, respectively.

\section{Evaluation of malondialdehyde levels}

MDA level measurements were performed using TBA test method by spectrophotometric examination based on changes in purple color due to the reaction of the formation of thiobarbituric acid-MDA complex. Spectrophotometric examination was performed at a wavelength of $530 \mathrm{~nm}$ by measuring Thio Barbituric Acid Reactive Substance (TBARS) levels. MDA levels were measured from venous blood samples, which were taken as much as $4 \mathrm{ml}$, then put in a tube, centrifuged at $3000 \mathrm{rpm}$ for 10 minutes at $4^{\circ} \mathrm{C}$. Serum separated from red blood cells is then used to examine MDA levels. The examination is carried out on the same day as blood sampling. If the examination cannot be done immediately, then the serum sample will be stored in a freezer with a temperature of $-80^{\circ} \mathrm{C}$.

\section{RESULTS AND DISCUSSION}

\section{A. Histopathological evaluation}

Following terminal surgery, testis was removed, divided into two parts, one of them was fixed in $10 \%$ formalin solution. After fixation process, testis organ was dehydrated in ethanol with increasing concentration and then embedded in paraffin block using tissue embedding console. After the testis organ embedded in paraffin block, the block was sectioned at $5 \mu \mathrm{m}$ thickness by using microtome and put on the object slide.

The specimens were deparaffinized by using xylene, continued with rehydration process using ethanol in reducing manner $(95 \%, 90 \%, 80 \%$, and $70 \%$, respectively). After washing with tap water, specimens were stained by hematoxylin for 1 minute, continued with washing step using water. After that, specimens were stained by eosin for 5 minutes and then washed with water. At the final step, specimens were dehydrated by using ethanol in concentration increasing manner, and cleared with xylene. Specimens then mounted and covered with cover glass. The preparation of histopathological specimenswas conducted in the Laboratory of Pathology Anatomy, Faculty of Medicine, Universitas Brawijaya.

All slides were observed under light microscope (Olympus BX-51) using 400x magnification (high power field). Each speciments were observed for 10 random hpf and analyzed for the determination of Spermatogonial cell counts.

TABLE 1.THE AVERAGE NUMBER OF SPERMATOGONIA IN EACH TREATMENT

\begin{tabular}{cccc}
\hline Groups & $\begin{array}{c}\text { Mean/Averag } \\
\text { e }\end{array}$ & Standard Deviation & p-value \\
\hline Control & 43.6750 & 3.99781 & 0.003 \\
Cycles 1 & 26.0500 & 2.28692 & 0.003 \\
Cycles 2 & 19.7500 & 1.45258 & 0.003 \\
Cycles 3 & 7.1500 & 1.19024 & 0.003 \\
\hline
\end{tabular}

\section{B. Statistical Analysis}

All data were analyzed using the one-way anova test, and the data presented as mean \pm SD or SEM. Data analysis was conducted by using software SPSS version 24.0 at confidence interval 95\%. Graphical data were made by using GraphPad Prism version 8.2.1.

\section{The effects of BEP chemotherapy on Spermatogonial cells}

The average number of Spermatogonia cells obtained in the control group had the highest amount compared to treatment groups 1, 2, and 3 (Table 1). The highest average number of Spermatogonia cells in the control group was $43,675 \pm 3.99(\mathrm{p}=0.003)$, and a significant decrease in the average number of 
Leydig cells occurred in the third cycle treatment of 7,150 \pm $1.19(\mathrm{p}=0.003)$ (table 3). The average number of Spermatogonia cells in the first cycle group was 26,050 \pm $2.28(\mathrm{p}=0.003)$ and the third cycle was $7,150 \pm 1.19(\mathrm{p}=$ 0.003 ) (table 1).

\section{The effects of BEP on MDA levels}

The highest average of MDA level in P3 treatment was $0.2858 \pm 0.14(\mathrm{p}=0.001)$ and the lowest average of MDA level in P2 treatment was $0.0922 \pm 0.05(\mathrm{p}=0.001)$. The average value of MDA levels in the first cycle group was $0.147 \pm 0.02(\mathrm{p}=0.001)$ and the third cycle was $0.285 \pm 0.13$ $(\mathrm{p}=0.001)$ (figure 1$)$.

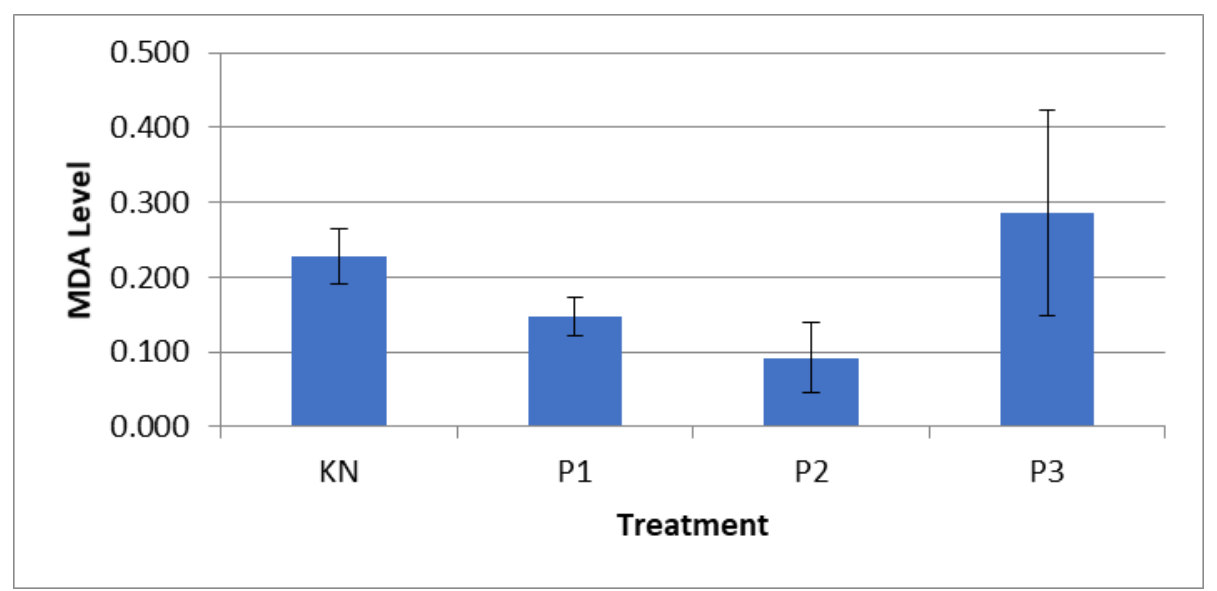

Fig. 1. Comparison of the average value of MDA levels in each treatment. A significant increase in MDA levels was found in the third cycle group. Negative control (KN), first cycle treatment (P1), second cycle treatment (P2), third cycle treatment $(\mathbf{P 3})$.

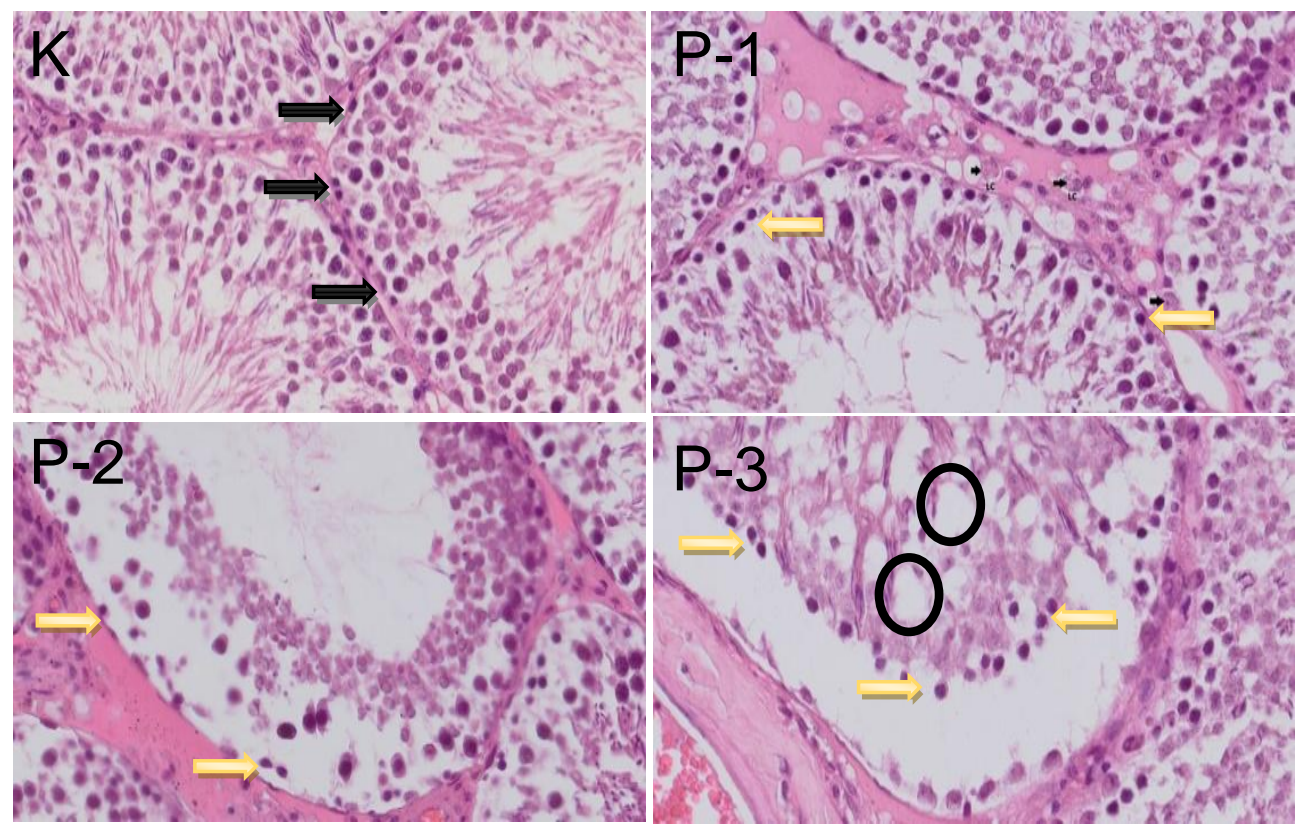

Fig. 2. Histopathological examination on testis seminiferous epithelium in rats. Sections were stained with HE and observed under light microscope using 400x magnification. A testicular section from control rat (K) showed normal seminiferous tubule organization (black arrows) and spermatogenesis. Testis of BEP-treated rats (P-1, P-2, P-3) showed degenerated seminiferous epithelium (yellow arrows) and germ cells. Severe abnormalities, the content of germ cells in tubules has decreased, sloughed immature germ cells into the lumen and extensive vacuolization (black circle).

\section{E. Testis histology}

Rats had treated with BEP were characterized by severe athropic and germ cell-depleted seminiferous tubules on cross-sections of testis compared to controls. In the second cycle of BEP chemotherapy, severe abnormalities begin to appear. The content of germ cells in the tubules has decreased, accompanied by the appearance of immature germ cells that enter the lumen, giant nucleated cells are formed, and accompanied by the presence of large vacuola bubbles (vacuolization) in the seminiferous tubules (figure 2).

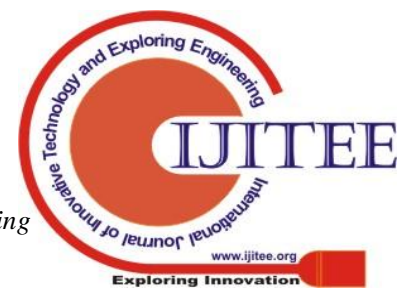




\section{DISCUSSION}

Oxidative stress is the most important part of the progression of infertility in men because it can cause rapid cell division and can consume mitochondrial oxygen in testicular tissue, which results in higher unsaturated fatty acids in testicular tissue. Oxidative stress can also induce a buildup of free radicals that produce tissue damage to the mitochondria, thereby reducing the function of the mitochondria and DNA mutations. ${ }^{12}$ Lipid peroxidation can damage cell membrane permeability and damage the whole of the cell. Cell membranes damaged by free radicals cause loss of protective function of cells and cells become at risk for exposure to external exposure.

Exposure to BEP chemotherapy can cause sperm DNA damage, induce the breakdown of single and double strand DNA, reduce chromatin density, induce telomere shortening in the spermatogenesis stage, damage to seminiferous tubular structures and testicular organs, and cause change in hormone levels in the blood that occurs after 3 to 6 months of BEPchemotherapy. ${ }^{10,11}$ This study shows similar results, where in the second cycle of BEP chemotherapy, severe abnormalities begin to appear. The content of germ cells in the tubules has decreased, accompanied by immature germ cells that enter the lumen (Figure 2 (P-2, P-3)). The number of cells in the tubules, which are Spermatogonia cells, also decreased. The least number of cells was found in the third cycle treatment (table 1).

Administration of short-term BEP chemotherapy can induce oxidative stress, where long-term administration can stimulate the formation of oxidative stress response expression in the testes, which eventuallycan induce damage from germ cell pathways. ${ }^{5}$ This study also gave an appropriate result in the long-term exposure to BEP chemotherapy, causing atrophy of the seminiferous tubules accompanied by immature germ cells in the lumen, the formation of giant nucleated cells, and accompanied by the appearance of large vacuolization within the seminiferous tubules at the end of the third cycle (Figure 2 (black circle)).

BEP is an anticancer drug that can cause abnormalities of Leydig cells, cause toxicity due to disruption of membrane cell permeability, oxidative damage, decrease antioxidants, and cause fat peroxidation. ${ }^{13}$ Prolonged administration of BEP chemotherapy can also induce lipid peroxidation and cell apoptosis, which results in cell death. ${ }^{12}$ This degradation of saturated fatty acid peroxides causes the production of MDA, which is used as a marker for oxidative damage from lipids. It is also consistent with this study which explains that the third cycle treatment there was an increase in high MDA levels when compared to the control group, the first cycle treatment, and the second cycle treatment (figure 1).

\section{CONCLUSION}

We concluded that there were significant differences between control compared BEP-treated rats. In the first cycle of BEP chemotherapy, there has been a decrease in the number of Spermatogonia cells. A significant increase in MDA levels occurs at the end of the third cycle. Exposure to the third cycle of BEP chemotherapy is more destructive than the first cycle and the second cycle.

\section{ACKNOWLEDGMENT}

This study was supported by Department of Urology Faculty of Medicine Brawijaya University Malang and Saiful Anwar General Hospital Malang.

\section{REFERENCES}

1. Manecksha RP, Fitzpatrick JM. Epidemiology of testicular cancer. BJU international. 2009 Nov;104(9b):1329-33.

2. Rosen A, Jayram G, Drazer M, Eggener SE. Global trends in testicular cancer incidence and mortality. European urology. 2011 Aug $1 ; 60(2): 374-9$.

3. Jørgensen N, Vierula M, Jacobsen R, Pukkala E, Perheentupa A, Virtanen HE, Skakkebaek NE, Toppari J. Recent adverse trends in semen quality and testis cancer incidence among Finnish men. International journal of andrology. 2011 Aug;34(4pt2):e37-48.

4. Feldman DR, Patil S, Trinos MJ, Carousso M, Ginsberg MS, Sheinfeld J, Bajorin DF, Bosl GJ, Motzer RJ. Progression-free and overall survival in patients with relapsed/refractory germ cell tumors treated with single-agent chemotherapy: Endpoints for clinical trial design. Cancer. 2012 Feb 15;118(4):981-6.

5. Delbès G, Chan D, Pakarinen P, Trasler JM, Hales BF, Robaire B. Impact of the chemotherapy cocktail used to treat testicular cancer on the gene expression profile of germ cells from male Brown-Norway rats. Biology of reproduction. 2009 Feb 1;80(2):320-7.

6. Kilarkaje N, Mousa AM, Al-Bader MM, Khan KM. Antioxidants enhance the recovery of three cycles of bleomycin, etoposide, and cisplatin-induced testicular dysfunction, pituitary-testicular axis, and fertility in rats. Fertility and sterility. 2013 Oct 1;100(4):1151-9.

7. Jahnukainen K, Ehmcke J, Hou M, Schlatt S. Testicular function and fertility preservation in male cancer patients. Best practice \& research Clinical endocrinology \& metabolism. 2011 Apr 1;25(2):287-302.

8. Cheung HH, Yang Y, Lee TL, Rennert O, Chan WY. Hypermethylation of genes in testicular embryonal carcinomas. British journal of cancer. 2016 Jan;114(2):230.

9. Marcon L, Hales BF, Robaire B. Reversibility of the effects of subchronic exposure to the cancer chemotherapeutics bleomycin, etoposide, and cisplatin on spermatogenesis, fertility, and progeny outcome in the male rat. Journal of andrology. $2009 \mathrm{Jul}$ 8;29(4):408-17.

10. Liu M, Maselli J, Hales BF, Robaire B. The effects of chemotherapy with bleomycin, etoposide, and cis-platinum on telomeres in rat male germ cells. Andrology. 2015 Nov;3(6):1104-12.

11. Paoli D, Gallo M, Rizzo F, Spano M, Leter G, Lombardo F, Lenzi A, Gandini L. Testicular cancer and sperm DNA damage: short-and long-term effects of antineoplastic treatment. Andrology. 2015 Jan;3(1):122-8.

12. Motawi TM, Sadik NA, Refaat A. Cytoprotective effects of DL-alpha-lipoic acid or squalene on cyclophosphamide-induced oxidative injury: an experimental study on rat myocardium, testicles and urinary bladder. Food and Chemical Toxicology. 2010 Aug 1;48(8-9):2326-36.

13. Martins NM, Santos NA, Curti C, Bianchi MD, Santos AC. Cisplatin induces mitochondrial oxidative stress with resultant energetic metabolism impairment, membrane rigidification and apoptosis in rat liver. Journal of Applied Toxicology: An International Journal. 2009 Apr;28(3):337-44

\section{AUTHORS PROFILE}

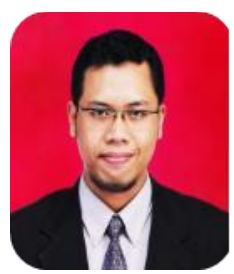

dr. Taufiq Nur Budaya Sp. U has completed his urologist degree from Airlangga University, He is currently working as urology staff at Urology Department, Brawijaya University, Malang. He has released 2 books about BPH and Malignancy in Urinary Tract. 


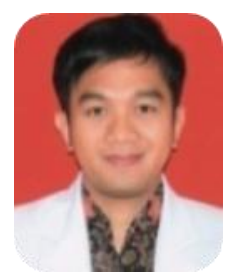

dr. I Gusti Agung Thede Surya Putra Sp. U has completed his urologist degree from Brawijaya

University, Malang.

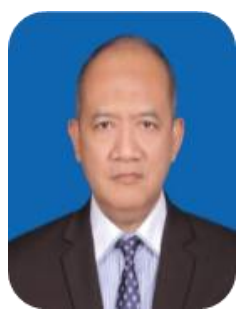

dr. I Gusti Agung Thede Surya Putra Sp. U has completed his urologist degree from Brawijaya University, Malang.

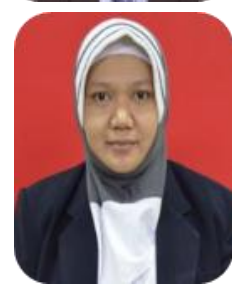

dr. Kenty Wantri Anita Sp. PA has completed his pathology anatomist degree from Diponegoro University. She is currently working as pathology anatomy staff in Pathology Anatomy Department, Brawijaya University, Malang. 